\title{
Innovative approaches to building housing system resilience: A focus on the Australian social and affordable housing system.
}

Dr Judy A. Kraatz

Abstract

Housing is a complex, integrated network of social and economic infrastructure. Improving the overall provision, suitability and socio-economic resilience of our housing system is needed. This requires new typologies to accommodate changing demographics, and to address the critical issues of access and affordability.

Current pressure across the housing system is resulting in long waiting lists for social housing and a lack of affordable rental housing. Meanwhile we have an oversupply of some social housing types, indicating a mismatch between what is being supplied, and what is needed. Tiny houses, elder co-housing, inclusionary zoning and the use of vacant infrastructure are some of the emerging approaches available to address current system shortfalls and build future system resilience. Such innovations pose many challenges, including for our planning systems.

This paper discusses these approaches, with a focus on both asset and social needs, in order to inform the development of a more accessible, robust and resilient social and affordable housing system. This is done in the context of recent research which developed social procurement criteria which aim to enable more expansive thinking by those developing policy and delivering outcomes in this space.

Keywords: social housing; affordable housing; tiny houses; elder co-housing; social procurement 


\section{Introduction}

Tiny houses, elder co-housing, inclusionary zoning and the use of vacant infrastructure are just a few of the potentially transformative means through which we could help to build the social and economic resilience of the Australian social and affordable housing system. These four areas are highlighted discussed in this paper due to their inherent potential to deliver on social as well as economic outcomes. The social and affordable housing system is a complex one, impacted by many variables including: three layers of Government-based policy; funding and financing arrangements; labour market and supply chain dynamics; changing demographic needs; evolving community expectations; and potentially disruptive technologies which will impact across all these elements. It thus encompasses the social, environmental and economic realms.

In this paper, the author contends that by taking a more diverse approach to procurement, system resilience can be improved. Through this, the ability of the social and affordable housing system 'to absorb change and disturbance' will be enhanced, and thus outcomes improved (Cutter et al. 2008). To do this the paper considers the need for improving access to social and affordable housing through the lens of social procurement (Kraatz 2018a, Kraatz 2018b).

Past procurement approaches have focussed on housing as an asset. More recently State and Territory Governments have focussed on providing social and affordable housing through a broader person-centred lens (Chilvers 2017). This acknowledges that access to safe and secure housing provides individuals with a significant array of other benefits. Having a home provides a stable base from which to better engage with employment, education, family and the community, and fosters improved health and well-being (Kraatz, Mitchell et al. 2015, Kraatz and Thomson 2017). In addition, housing has now become an internationally traded 
commodity (Farha 2017), shifting the focus from housing as basic human right and an element of key social and economic infrastructure to a traded commodity.

The four emerging approaches discussed in this paper can be used to target specific needs in specific locations, rather than following global or even nation-wide trends. They can also deliver social along with economic benefit through considering broader social deliverables. This will however require more awareness of the potential for social value-add to traditional asset-based procurement approaches (Kraatz 2018b). The social procurement criteria, presented later in this paper, have been developed to leverage such potential.

\section{Background}

Building housing system resilience is needed to create a more adaptive system that can better absorb impacts (e.g. growing population with changing needs), and that can enable the system 'to reorganize, change, and learn', not only as a consequence of disaster (Fayazi and Lizarralde 2013). This paper explores the idea that a diversity of housing typologies fosters socio-economic housing resilience (Zandt et al., 2012, Thomas 2013). Whilst resilience is most often discussed in terms of recovery from a disaster, it is considered here as a means to better 'measure of the persistence of systems and their ability to absorb change and disturbance and still maintain the same relationships between populations or state variables' (Cutter et al., 2008).

The current need for greater diversity in supply options for social and affordable housing is highlighted in the extensive waiting lists and lack of affordable housing currently experienced in most States and Territories of Australia.

- ' 189,400 households (are) awaiting social housing allocation at 30 June 2017' (Australian Institute of Health and Welfare 2018). 
- 'A single person on Youth Allowance and Newstart would find it almost impossible to find an affordable home anywhere in Australia, whether regional or metropolitan' (Anglicare Australia 2017).

- Over the next 20 years '727,300 additional social dwellings will be required' (Lawson, Pawson et al. 2018).

- There is a gap between underlying demand and supply of between 200,000 to 550,000 houses (depending on data source), with 2016 and 2017 housing construction matching population growth but not addressing existing shortfalls (Community Housing Industry Association 2018).

Historically the social housing sector provided housing for those on very low to medium incomes. Today, this sector typically can only meet the needs of those on very low incomes and with priority or special needs. This is exposing those on low and medium incomes to rental stress in the private rental market, and to a home ownership market often beyond their reach (Figure 1).

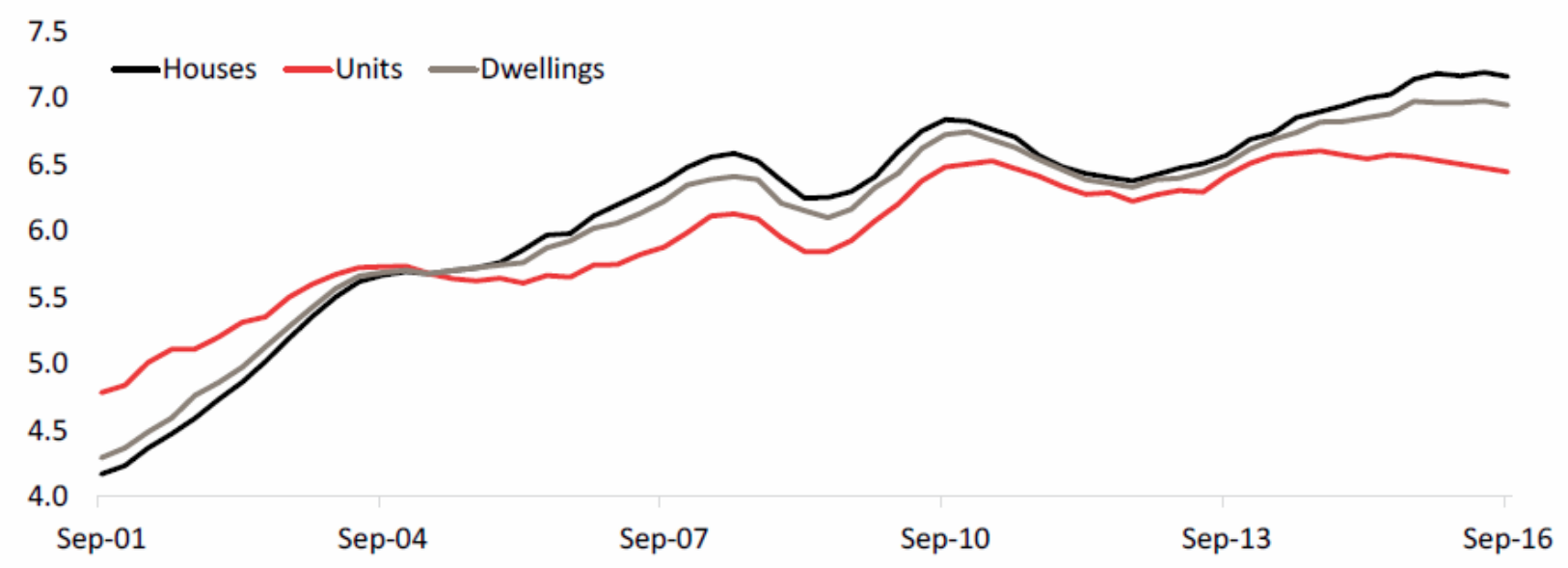

Figure 1 - National Price to Income Ratio (CoreLogic 2016)

In addition to a challenging marketplace, the demographics of the Australian population seeking housing is also changing: the population is aging; household composition 
is changing; cities are continuing to be the key growth areas; and home ownership is declining. (Kraatz, Baro et al. 2018). These changes are largely due to longer life expectancy; migration; and growing household diversity (e.g. one person and multigenerational households). These general trends are altering the composition of households and affecting lifestyles and the demand for appropriate housing. These trends are further affecting the capacity of governments and Community Housing Providers (CHPs) to effectively address specific needs. The type of available housing is also failing to keep pace with these changing demographics. This poses a difficult asset scenario for portfolio owners who are facing a mismatch between of housing types and tenant needs. This is also an unsatisfying outcome for residents, who are needing more efficient and accessible housing and now also wanting more sustainable, community-based options.

Couple with this is a major change across Australian jurisdictions, from a traditional asset focus to person-centred solutions which provides housing as a part of a longer-term whole-of-life strategy (Chilvers 2017, Queensland Department of Housing and Public Works 2017a). Government agencies are now invested in procurement approaches that look beyond the economic to the social realm. This requires a better understanding of broader impacts of housing and homeless. The breadth of likely impacts can be effectively considered across 9 domains (community, economy, education, employment, environment, health and well-being, housing, social engagement and urban amenity) (Kraatz et al. 2015).

All this is requiring additional, alternative and innovation procurement, and funding and financing approaches. It is into this environment that innovative approaches such as tiny houses, elder co-housing, inclusionary zoning for social and affordable dwellings (including value uplift), and the use of vacant infrastructure (including pop-up shelters) are being considered as possible solutions. Such emerging approaches bring with them several challenges including: to government housing and planning agencies establishing policy and 
strategy; to not-for-profit (NFP) agencies delivering affordable rental housing and in a changing regulatory and governance environment; and to the private sector seeking to partner with these organisations and also deliver housing stock with market longevity.

\section{Addressing current system challenges}

There are several challenges to consider when looking to improve access to social and affordable housing in Australia. This is a complex issue of which 4 elements are discussed in this paper, each of which relates to housing diversity and system resilience:

(1) The changing demographics of our population - tracking demographics as a tool for identifying future housing needs is a goal for many organisations, though in reality difficult to realise and implement, given the long-term investment required in housing assets (Kraatz and Jayawardena 2018).

(2) The legacy of past housing types, and changing demographics and community expectations brings impacts on household composition and needs (Kraatz, Baro et al 2018).

(3) The rise of housing as commodity - from around 2011 significant and unanticipated international pressure was brought to bear in relation to the affordability of Australia housing (Farha 2017).

(4) Planning as a mechanism for change - the planning system is a critical mechanism for enabling changes in the housing system, requiring integrated action across government agencies, and between the public, private and not-for-profit (NFP) sectors and the community.

\section{Changing demographics}

Four key demographic trends have been highlighted, which are placing increased pressure on our housing system: an aging population; changing household composition; cities 
as key growth areas; and a decline in home ownership. The Australian population is aging, with the over 65 group is expected to almost double in size by 2030 (Cigdem, Wood et al. 2015) (Figure 2).

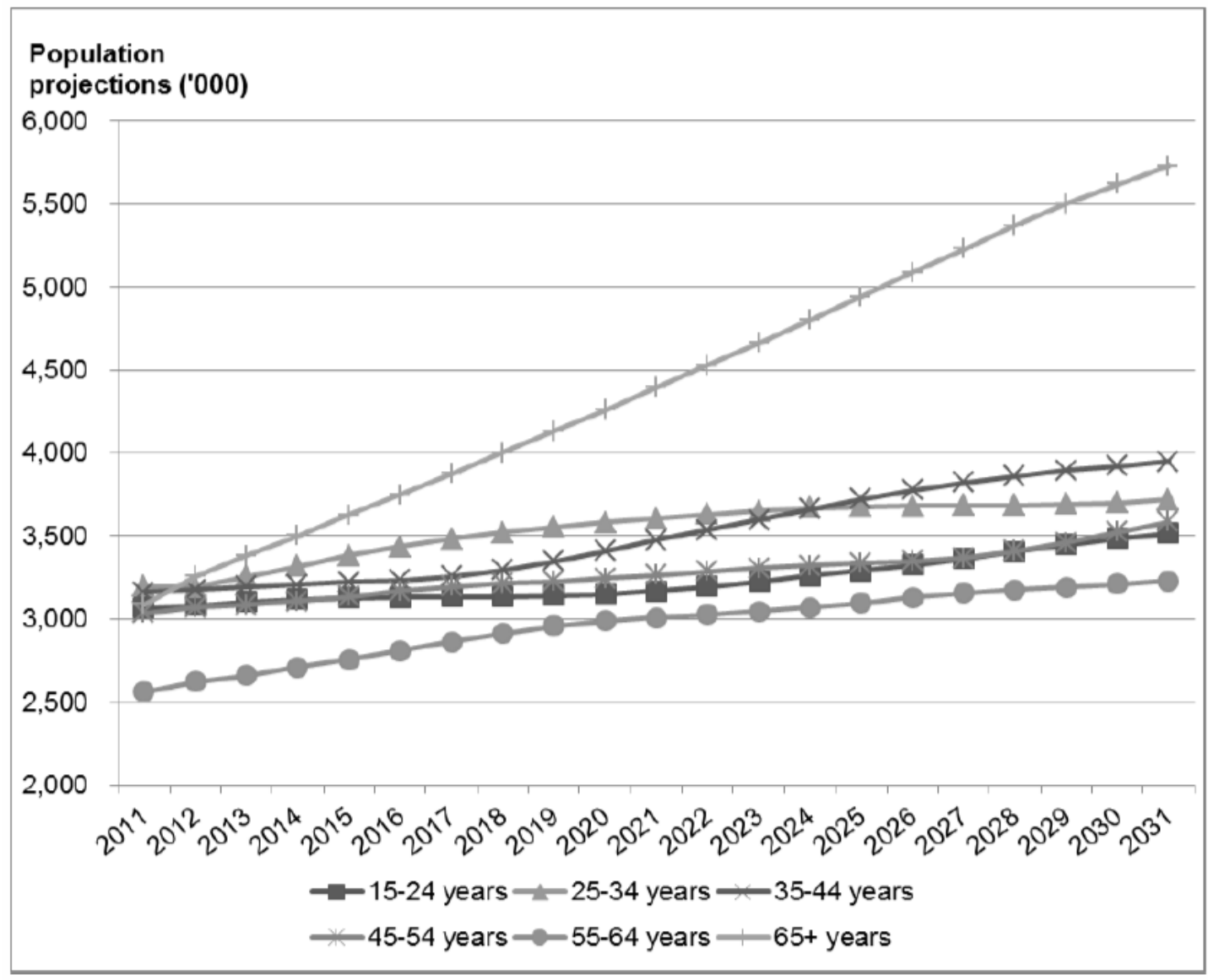

Source: 2011 estimate from the 2011 Census, 2012 to 2031 estimates from Australian Bureau of Statistics population projection time series $\mathrm{B}$

Figure 2 - Population projections by age band, 2011-31(Cigdem, Wood et al. 2015)

Alongside this, household composition is changing, with single person households projected to grow from 2.1 million in 2011 , to between 3.3 to 3.5 million in 2036 (61 to 65 percent growth) (Australian Bureau of Statistics 2015). In addition to this is a reported growth in social isolation. Findings of a national survey conducted in mid-2018 found 'one in two (50.5 percent) Australians feel lonely for at least one day in a week, while one in 4 (27.6 
percent) feel lonely for three or more days' (Australian Psychological Society and Swinburne University 2018).

Our capital cities are now home to around two-thirds of all households, from 65 percent in 2011 to a projection of 68 percent in 2036 (Australian Institute of Health and Welfare 2018). And whilst these cities are growing, there has also been a significant downward trend in homeownership over the past 30 years in Australia, with a decline from 71 percent in 1994-1995, to 62 percent in 2013-2014, with outright ownership falling from 42 percent to 31 percent (Australian Bureau of Statistics 2016, Australian Institute of Health and Welfare 2017).

\section{Challenging traditional housing typologies}

In this context, low density suburban-based housing typologies need challenging in order to effectively address housing supply shortfalls and changing household composition. Several trends are evident including: a move towards resource efficiency (including energy and water efficiency and better access to active or public transport); recognising and addressing the growth in average home size in Australia; acknowledging the benefits of greater community and social integration; and improving access both into and within our homes to improve usability across peoples' life spans through liveable (or universal) housing design (Kraatz, Baro et al. 2018).

A trend to more environmentally sustainable housing and community designs has been occurring over the past 30 years. This is now maturing, with energy, water and resource efficiency becoming an integral part of the design language in some segments of the housing market (GBCA 2015, Xia 2015, Yang and Yang 2015). This is however not universal. For example, much of our medium and high-density unit stock, and many outer-ring housing developments still fail to address basic principles of water, energy, materials and transport 
efficiency. The private car remains the dominant form of transport in this country, with associated impacts in terms of emissions, household budgets and congestion costs.

The average size of our housing in Australia has also grown considerable over the past 30 years (Figure 3). Australian homes (average of $189.9 \mathrm{~m}^{2}$ ) being second only to those in America $\left(204.3 \mathrm{~m}^{2}\right)$ in terms of size. This is well ahead of other countries, for example, the average home size in Germany is $96.6 \mathrm{~m}^{2}$, and Hong Kong, $43.6 \mathrm{~m}^{2}$ (Commsec 2017).

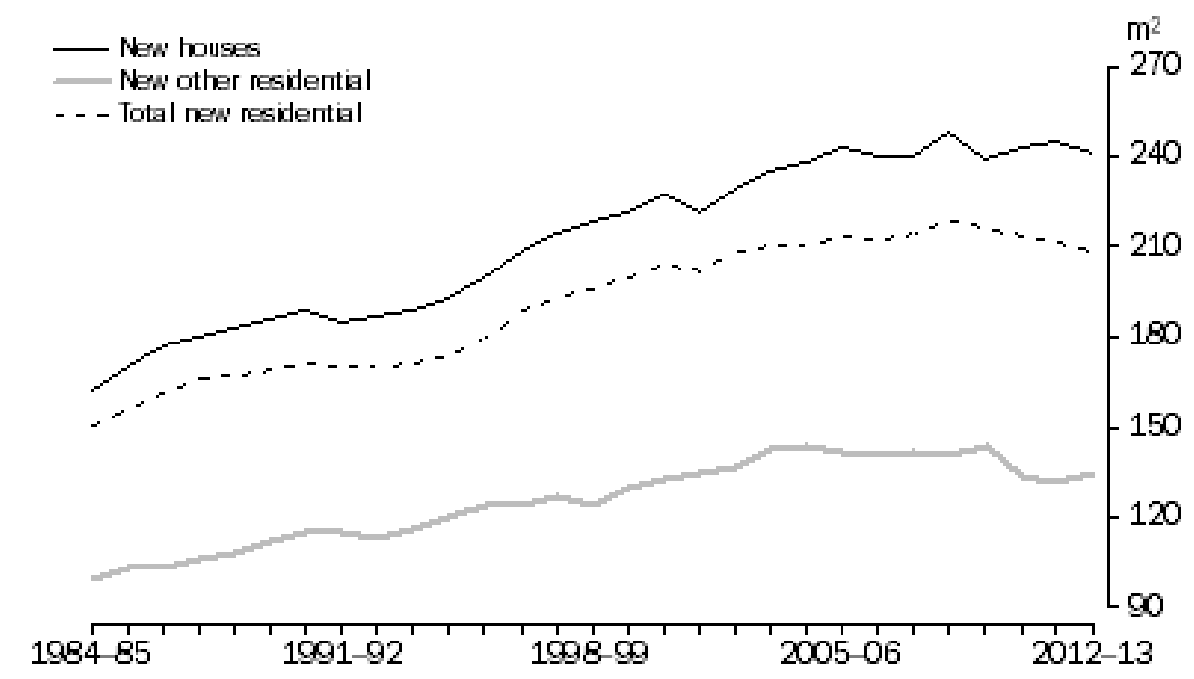

Figure 3 - Average floor area of new residential dwellings, Australia (Australian Bureau of Statistics 2013)

There is also a trend towards building community and enhancing social connectedness. State and Local Governments around Australia, whilst at times promoting higher densities, are also seeking to build stronger avenues for community and social engagement. Conversations around the 'missing middle' are evidence of this. Governments across Australia are seeking housing solutions which sit between the traditional suburban house, and high-density unit blocks (Cheng 2016, Queensland Department of Housing and Public Works 2017). Examples of proposed solutions include duplexes, courtyard apartments and townhouses which also address sustainability, liveability and walkability issues.

As noted, addressing community and social connectedness is becoming increasingly important, given the most recent focus on growing social isolation. This has been recently 
highlighted by several sources (Families Australia 2018, Wahlquist 2018, Walker 2018).

Demographic trends showing a strong shift in the Australian population towards single person households. We need caution when and if responding simply with a greater supply of single bedroom units, and ask if this is sustainable as a society, and for individuals. Are there other policy initiatives we should be investigating before committing to long-term housing portfolios which support this way of living - such as tiny houses and elder co-housing?

Liveable housing design (Livable Housing Australia 2019) (also referred to as universal design) needs to be an integral part of this conversation to improve the resilience of housing infrastructure across the household lifespan. Several benefits ensue around such access, whether for young families, short term sickness or long-term disabilities, and reducing the need for costly renovations as people age at home.

\section{Housing as commodity}

A further key element which has been impacting the Australian housing market in recent years is the financialisation (i.e. commodification) of our housing stock. In 2017, the United Nations (UN) Special Rapporteur on Adequate Housing provided a report on the impact of private and international investment in housing, and the pressures this was placing on traditional housing markets across the globe.

'The Special Rapporteur suggests that, as a way forward, States must redefine their relationship with private investors and international financial institutions, and reform the governance of financial markets so that, rather than treating housing as a commodity valued primarily as an asset for the accumulation of wealth they reclaim housing as a social good, and thus ensure the human right to a place to live in security and dignity'. (Farha 2017)

Sydney was identified in this report as one of several 'hedge' cities in which housing prices had increased by over 50 percent from 2011 until the time of the report. This created 'vast amounts of increased assets for the wealthy while making housing unaffordable for most households not already invested in the market' (Farha 2017). Hong Kong, London, Munich, 
Stockholm and Vancouver were noted as other such cities. These cities are seen as 'prime destinations for global capital seeking safe havens for investments'. This however inflates housing prices beyond that which residents of those cities can afford, 'excluding moderateand low-income households from access to homeownership or rentals due to unaffordability' (Farha 2017). This report notes that these households (often keyworkers ${ }^{1}$ ) are then pushed to outer suburbs, away from the employment and services.

\section{Planning as an agent for change}

Solutions to all these above issues can be found with innovative approaches. This requires rethinking however, across several areas from policy, to procurement, to funding and financing, and to our planning systems and mechanisms. It requires strong leadership and collaboration both across government agencies, and between the public, private and not-forprofit (NFP) sectors.

Greenhalgh and Bosman (2016) discuss several ways in which planning policies and practices have been used in recent years to increase the supply of affordable housing. This includes: streamlining the development approval process to reduce costs to the construction industry; providing incentives to developers to deliver affordable housing through density bonuses and relaxations; and requiring a specified percentage of social and/or affordable housing in a given development, that is, inclusionary zoning (Greenhalgh and Bosman 2016). They discuss the case of the Urban Land Development Authority (ULDA) in Queensland, which was established 'to deliver a range of housing products to meet the changing needs of the community'. ULDA also had a mandate to 'attach conditions of sale to land to require a

\footnotetext{
1 'People who are ineligible for public housing (if it exists in these areas), yet do not earn enough to afford to buy a home and who may have affordability problems in the private rental market in a location relatively convenient to their workplace' (Yates et al., 2005),
} 
set contribution of affordable housing and meet other Government policy outcomes that improve access to housing' (Greenhalgh and Bosman 2016). Since its closure in 2013, its remit was in part transferred to Economic Development Queensland (EDQ). The authors note however that there was "no mechanism to retain contributed affordable housing or targeting of affordable product to 'eligible households' (p.219)", which seems fundamental to ensuring on-going benefit.

By way of comparison, we can look at the example where LandCorp in Western Australia (WA) (Kraatz, Baro et al. 2018). LandCorp is a State-based land and development agency which works to 'identify, design and implement major land and infrastructure projects through a sustainable approach to development' (LandCorp 2019a). This is done through collaboration with private and public sector partners, and in the context of Government planning directives. The WGV 'Innovation through demonstration' precinct in Fremantle is an example of one such partnership, with the City of Fremantle (LandCorp 2019b). This cooperative housing development is designed according to WGV Design Guidelines and Sustainability Rebate Package (LandCorp 2015) and offers a variety of new approaches, such as family and row houses, apartment studios (SHAC), and a cohousing development. One example at this precinct is the Gen Y Demonstration Housing Project (LandCorp 2019c), consisting of three interlocking one-bedroom, one-bathroom apartments that appear as a single house on a 250 sq. m. block. The project is designed specifically with liveability, accessibility, sustainability and affordability in mind and was offered for sale to first home buyers earlier this year. The Step-up Affordable Housing design competition is a further example of how LandCorp is using its position and power to influence new, more affordable, planning and design outcomes for medium density developments (LandCorp 2016).

Planning mechanisms are powerful tools, and can be used to enable more independent and flexible solutions. In the US for example, Evans identifies zoning as a key issue for tiny 
housing. 'Three overarching methods of legally accommodating tiny and small homes in urban areas have been identified: as accessory dwelling units (ADUs), in tiny house-specific communities, and as urban infill among various other housing types (Evans 2018). She concludes with three recommendations to inform planning considerations, being: (i) emphasise affordability; (ii) consider the impact on property values potentially favouring 'tiny house-specific developments' over integration; and (iii) developing classification and regulation structures regarding 'tiny houses on wheels'.

In Australia, in a recent survey around tiny houses, Shearer (2017) reported that 'planning scheme inflexibility and complexity' were key planning system barriers to tiny housing. One survey respondent noted the tiny house as 'a way to enable ease of financing', but 'this means that if a local government is serious about affordability, planning regulations need to change to enable freehold titling and increased density without having to go through costly and time-consuming development approval processes'. Shearer highlights the potential of tiny houses 'either as tiny house villages, or by relaxing planning schemes to allow owners and tenants to situate well-designed tiny houses on suburban lots' (Shearer 2017).

\section{Emerging housing options}

This paper discusses just four of the many emerging approaches available to address our social and affordable housing shortfall. A listing of possible housing types reveals to potential depth and breadth of available solutions: boarding homes, caravans, cooperatives, co-housing, detached housing, dual/multiple occupancy, duplexes, granny-flats, high-rise apartments, hostels, low-rise units, mobile homes, micro-lot developments, mixed-use developments, pop-up shelters, remote community housing, semi-detached housing, shelters, small lot developments, studio apartments terraces, tiny houses and townhouses. The four chosen - tiny houses, elder co-housing, inclusionary zoning and the use of vacant 
infrastructure - have been highlighted as they potentially pose the greatest challenges to current thinking and delivery models.

\section{Tiny houses}

Tiny housing is growing in popularity as a housing model that is 'affordable, flexible and sustainable' (Nobel, Carter et al. 2017). Vail (2016) describes tiny houses in the United States as a part of a movement to downsize the space lived in, order to lead simpler lives with less financial burdens (Vail 2016). It also enables potentially more sustainable construction materials and methods due to the smaller footprint. As such they have historically provided accessible housing options post-war or post-disaster (Nobel, Carter et al. 2017).

Recent Australian research reveals the growth in interest in tiny houses and asked 'who wants them and why?' (Shearer 2017). Responses include: strong demand for urban living; too expensive property in preferred area; wanting to reduce overall debt, and not wanting a mortgage; wishing to downsize, and housing too expensive in general' (Shearer 2017). This assessment fits with those demographic trends noted in this paper. Also, of note is the interest in tiny houses by women over 50 (the author notes that this could be a result of sampling bias), though this group is also 'the fastest-growing demographic for homelessness in Australia'.

In follow-on research, Shearer and Burton seek to provide a definition for this emerging typology. Some generalised key characteristics include: very small dwellings (less than $40 \mathrm{~m}^{2}$ ); built on a mobile foundation in a temporary location; a design ethos aligned with affordability, and for some on sustainability and community; historically often owner-builder in nature; used as a primary residence; and with a focus on reducing cost and exposure to debt risk (Shearer and Burton 2018). The authors consider that they were in part 'a response to restrictive planning laws, such as mandatory consumption laws which required minimum room and house sizes, connection to utilities and of course, ownership of land'. 
Tiny houses are also seen and/or promoted as a more acceptable option to traditional forms such as caravan parks in the context of middle-class housing aspirations. 'Tiny house living has moved beyond the fringe and into the mainstream, with a growing number of municipalities permitting tiny houses, and an increasing number of bespoke tiny house construction companies active in the market' (Shearer and Burton 2018). The Netherlands are now using (prefabricated and temporary) tiny housing to help address public housing shortfalls for low income residents of Rotterdam (O'Sullivan 2018).

Despite this mainstreaming however in some countries (including the United States and the United Kingdom), regulations around tiny houses in Australia vary between States and across Local Government areas. They also face challenges with regards to the National Construction Code (Australian Tiny House Association NA). So whilst there is significant motivations for this housing type, and capacity to address the social and affordable housing shortfall in Australia, there are still significant issues to be addressed to mainstream this niche solution, particularly in terms of all layers of regulatory mechanisms. In a step forward, in March 2018 the Fremantle Council gave final approval to the Freo Alternative - Big Thinking about Small Housing. Proposed changes promote a wider choice for infill housing in Fremantle's suburban areas and facilitates alternatives such as tiny houses (City of Freemantle 2019).

\section{Elder co-housing}

Trends in the over sixty-five age group in the US show that: the percentage of older individuals living with their children has been decreasing since the 1950s; and Baby Boomers $^{2}$ are less likely to have children and more likely to be single (Glass 2013). Glass highlights that 29.3 percent were identified as living alone, in neighbourhoods 'increasingly

\footnotetext{
${ }^{2}$ Typically considered to be those born between 1946 and 1964.
} 
comprised of superficial and changing networks'. Loneliness was identified as a problem in the US, though the recent the 2018 Loneliness Report in Australia finds this group to be the least lonely of the Australian population (Australian Psychological Society and Swinburne University 2018). As discussed previously in this paper, recent Australian research finds a strong trend in this country towards single person households with housing agencies and the market are thus currently moving to address the need for additional 1-2 bedroom homes (Kraatz, Baro et al. 2018). This research also highlights an aging population. Before we make the step to providing more single bedroom and studio apartments however, to address this gap in supply, we need to ask if this is a sustainable solution for a society, and for individuals.

One approach to addressing this trend is through elder-focussed, self-directed intentional communities (EIC). 'Older adults consistently indicate a preference to live in their own homes. The EIC provides the potential opportunity to carry out this wish within a community of friends, while adding a supplemental layer of support not commonly found in the average neighborhood' (Glass 2014). Glass also reports on a mixed-methods longitudinal evaluation of Parkside (created by a group of elders based on the Dutch 'living group' approach) (Glass 2013). The author highlights residents' views on the process of community building, benefits, challenges and lessons learned (Table 1). 


\begin{tabular}{|c|c|c|c|c|c|}
\hline \multirow[b]{2}{*}{ Category } & \multicolumn{4}{|c|}{ No. } & \multirow{2}{*}{$\begin{array}{l}\text { Representative } \\
\text { Comments }\end{array}$} \\
\hline & 2008 & 2009 & 2010 & Total & \\
\hline \multicolumn{6}{|l|}{ Feature liked least } \\
\hline Location/physical layout & 48 & 35 & 24 & 917 & $\begin{array}{l}\text { Distance to international } \\
\text { airport; too small }\end{array}$ \\
\hline Organizational & 6 & 7 & 4 & 17 & $\begin{array}{l}\text { Too many meetings; } \\
\text { complicated } \\
\text { organizational structure }\end{array}$ \\
\hline Purpose/community & 8 & 8 & 10 & 26 & $\begin{array}{l}\text { Lack of common vision; } \\
\text { some folks don't } \\
\text { participate }\end{array}$ \\
\hline \multirow[t]{2}{*}{ Social } & 1 & 8 & 6 & 15 & $\begin{array}{l}\text { Lack of privacy; ratio of } \\
\text { men to women }\end{array}$ \\
\hline & 4 & 2 & 2 & 8 & Too small \\
\hline Total per year & 23 & 28 & 24 & 75 & \\
\hline \multicolumn{6}{|l|}{ Feature liked best } \\
\hline Location/physical layout & 15 & 14 & 6 & 35 & The location; the view \\
\hline Purpose/community & 8 & 18 & 23 & 49 & $\begin{array}{l}\text { Sense of community; } \\
\text { mutual support }\end{array}$ \\
\hline Social & 13 & 11 & 5 & 29 & $\begin{array}{l}\text { Collaboration/sharing } \\
\text { lives; the "social } \\
\text { security" of having } \\
\text { friends close }\end{array}$ \\
\hline Total per year & 36 & 43 & 34 & 113 & \\
\hline
\end{tabular}

Note: ${ }^{\text {a }}$ Respondents could mention more than one feature under each question

Table 1 - Number of respondents who mentioned features as liked least and like best by category (2008-2010) (Glass 2013)

\section{Inclusionary zoning}

There is currently significant variability to the application of inclusionary zoning targets across Australian States and Territories. Inclusionary zoning is defined as 'a land use planning intervention by government that either mandates or creates incentives so that a proportion of a residential development includes a number of affordable housing dwellings (AHURI 2017). Greenhalgh and Bosman (2016) note that this can be achieved through 'giving legislation a "head of power" to affect local planning schemes, specific State 
Planning Policies, or through the introduction of 'special purposes agencies', such as statutory land development authorities'.

The following are some of the current requirements across Australia (Greenhalgh 2015b, AHURI 2017):

(1) In New South Wales 2 percent is required in specified zones.

(2) South Australia (SA) requires a 15 percent provision of affordable dwellings in new housing developments, including 5 percent for high needs groups. 'South Australia (SA) delivered 5,485 affordable rental and low-cost home ownership dwellings between 2005-2015 through an inclusionary planning target applying to new residential areas, amounting to around 17 percent of SA's total housing supply' (Gurran, Rowley et al. 2018).

(3) The Queensland Housing Strategy 2017-20 Action Plan proposes that 'where surplus state land is developed for residential purposes, introduce inclusionary requirements so a proportion (5-25 percent) of new dwellings will be designated for social and affordable housing' (Queensland Government 2017b).

(4) In Western Australia (WA) a minimum 15 percent affordable housing is required on all government land and housing developments.

These targets are well below some of those set in other countries. For example, in the UK 'around 43 per cent of total affordable housing output (12,866 units) was delivered through inclusionary planning requirements in England between 2015-2016' (Gurran, Rowley et al. 2018), with London introducing a 50 percent target in 2004 (AHURI 2017). In the US, New York has floor area bonuses of 33 percent for 'new developments, or enlargements constituting more than 50 percent of existing floor area, within Inclusionary Housing designated areas that allocate at least 20 percent of their residential floor area for 
affordable housing' (AHURI 2017). Other US cities with such inclusions include: Detroit requiring 20 percent affordable housing in 'government funded projects or on governmentowned land'; and Boulder requiring 25 percent affordable housing in all developments (Rappaport 2018).

In the US, a joint effort between the Grounded Solutions Network, The Lincoln Centre and the National Housing Conference has resulted in an inclusionary housing calculator to 'allow communities to explore the relationship between various local incentives and the development of mixed income housing' (Grounded Solutions Network, Lincoln Institute of Land Policy et al. 2018, Inclusionary Housing 2018). They also provide an inclusionary zoning database map (Inclusionary Housing 2016) to enable communities to: 'learn more about the distribution of inclusionary housing programs; identify features and trends in inclusionary housing programs; find other programs just like yours; identify states that are in favour of inclusionary housing programs; and access datasets on inclusionary housing programs'.

In the Netherlands, 'the changing composition of the housing production, combined with a boom in house prices, led to an increase in land rents and land prices' (Buitelaar and Kam 2012). This further 'led to a critical moment in which questions were raised about the robustness of the way land for social housing was provided'. Following on from this confluence, a new Dutch Spatial Planning Act came into effect in 2008 which enable local authorities to designate land for social housing either via a percentage or location via a 'development plan' (Government of the Netherlands 2013). For success several issues need consideration: local policy variables; local economic context; land economics know-how; negotiation expertise within planning authorities; along with 'a willingness and a capacity to do so' (Buitelaar and Kam 2012). 
In Australia, mandating a 20 percent social and affordable housing target across all major housing developments, and on all government-owned land subject to sale and/or needs to be considered in order to address the overwhelming need for social and affordable housing in our cities. Importantly this can ensure a flow back to the community for the value uplift likely to occur from new residential developments, especially where these are integrated with key public transport or employment nodes.

\section{Using vacant infrastructure (including pop-up shelters)}

The use of vacant infrastructure, whether housing or commercial buildings, to provide short to medium term housing for those in need, is a further niche solution. This is nascent and yet to be fully explored or developed in the Australian context. Some past informal solutions include subletting, squatting and offering family and friends spare bedrooms.

In Spain, Rodríguez and Czischke (2016) called for Government, private and social sectors to work together to 'define new strategies to allow using vacant dwellings and ensure access to affordable housing in the Spanish context'. These authors highlight that of a total housing stock of about 25 million, 3.5 million remain empty. These vacant properties, as a result of the most recent property bubble, are predominantly located in either highly populated urban areas of strong residential demand, or coastal areas (secondary houses). Financial institutions own around 86 percent of this empty stock. Several social movements have emerged in Spain to protest evictions and address the use of vacant infrastructure and to promote political change 'to guarantee fundamental citizens' rights, as access to housing, among others' (Fernández Rodríguez and Czischke 2016). In a similar vein in Italy, 'an important issue, yet unsolved, consists in the selection of efficient tools, levies, fiscal constraints to reintegrate a portion of private vacant or unsold property into the rental affordable market' (Pogliani 2016). The author notes a recent governmental initiative to enable a portion of the stock to be 'rented at affordable prices and finances a special fund 
against arrears'. This targeted those dwellings transferred to banks due to building company bankruptcies.

This approach is also being promoted in Australia with the use of vacant infrastructure being championed in Melbourne by ex-Fraser's CEO, Richard Pradolin (Camero 2017). 'The Australian Bureau of Statistics estimates that there are 116,000 homeless people in Australia at any given time' (Pradolin 2018). Whilst more long-term solutions are needed, decisions need to be made as to how best to protect those in need on a more immediate basis. Examples provided by Pradolin include: the 'YWCA has been able to provide housing for 38 women over 55 years of age, in a building that would normally have been empty for several years'; and 'in Leichardt, NSW, where Uniting has repurposed a vacant aged care home pending demolition, into temporary accommodation for 30 women aged over 45 year'.

\section{Social procurement criteria: Enabling expansive thinking}

'Social procurement is when organisations use their buying power to generate social value above and beyond the value of the goods, services, or construction being procured' (Victorian State Government 2018). Building on this definition, each of the following present opportunities to address niche needs in specific locations, and can deliver social along with economic benefits:

(1) Tiny houses can provide affordable homes (with pursuant benefits such as improved health outcomes and social inclusion) for those who might otherwise have difficulties accessing the housing market, whether as an owner or a renter.

(2) Elder co-housing can provide an extended quality of life for those who may currently have limited options. 
(3) Setting minimum targets for inclusionary zoning can start to address the inequality embedded in the current developer and investor-led housing market.

(4) Using vacant infrastructure can derive both social and economic benefit from currently vacant properties.

While each of these approaches are likely to remain niche solutions (with the possible exception of inclusionary zoning), they can contribute to addressing diverse and changing needs, and to building resilience in the housing system.

The social procurement criteria developed in recent Sustainable Built Environment National Research Centre (SBEnrc) research are intended to help maximise the social benefits of traditional asset-based procurement processes (Kraatz 2018b). These criteria were designed to support those developing policy and program initiatives and delivering outcomes related to social and affordable housing in Australia. Here they are presented as a tool to help address the currently intractable problem of meeting Australia's social and affordable housing needs. When looked at through this lens, current approaches to address housing system issues are revealed as inadequate. Innovative and alternate approaches, at times nonmainstream, thus need further consideration and integration.

Earlier SBEnrc research ${ }^{3}$ has also informed their development. In particular the productivitybased conceptual framework ${ }^{4}$ and the 9 domains approach ${ }^{5}$ were integral to the development

\footnotetext{
${ }^{3}$ P1.31 Rethinking Social Housing and P1.41 Valuing Social Housing at www.sbenrc.com.au

${ }^{4}$ Benefits of providing safe and secure housing viewed through 4 productivity-based lenses: (i) to the tenant; (ii) to the macro economy; (iii) fiscal benefits; and (iv) non-economic benefits to social and environmental capital.

${ }^{5}$ Community, economy, education, employment, environment, health and well-being, housing, social engagement and urban amenity.
} 
of these 19 criteria. These are designed as a checklist that aims to ensure expansive and agile thinking, and to leverage possibly latent and disruptive opportunities.

In development, these criteria were tested on a cross section of social procurement approaches to illustrate how they can be used in policy, program and project development. This included looking at: (i) NSW Human Services Outcomes Framework (Chilvers 2016) and the person-centred journey through housing approach; (ii) Social Benefit Bonds and Youth Foyers as part of the Queensland Housing Strategy 2017-2027 (Queensland Department of Housing and Public Works 2017a) which aim to help youth at risk of homelessness; and (iii) WA Affordable Housing Strategy 2010-2020: Aiming Higher Strategy (Western Australia Housing Authority 2015) which brought together National Rental Assistance Scheme funding, the Keystart shared equity program and multi-sector partnerships to provide for a substantial expansion in supply of social and affordable housing in that State.

Current social procurement approaches in use across Australia were also investigated (Kraatz 2018). Traditional approaches include: public housing transfers and renewal; partnerships and joint ventures; housing for remote indigenous communities; the Community Housing Provider (CHP) model; shared equity/ownership; and Common Ground. In addition, there is a growing number of non-traditional approaches which have to potential to transform the way in which we consider social and affordable housing supply in this country. Along with the 4 highlighted in this paper, others include: value uplift; housing designed for those with a disability; cooperatives and co-housing; social impact/benefit bonds; and build to rent. To better leverage the potential of these new approaches, procurement systems need new tools and criteria to facilitate innovative thinking.

The 19 criteria been developed to promote more expansive thinking regarding procurement processes are shown in Table 2. It is not anticipated that all criteria will be relevant and/or applicable to all applications (whether policy or delivery), as there will be 
various unique considerations for each, such as demographic, locational, budgetary, political and the like. But it is recommended that each be considered as a part of early decisionmaking.

\begin{tabular}{l|l}
\hline System focus & Build partnerships \\
\cline { 2 - 2 } & Build housing pathways \\
\cline { 2 - 2 } & Build diversity in housing stock \\
\cline { 2 - 2 } focus & Build financial capacity of system \\
\hline \multirow{4}{*}{$\begin{array}{l}\text { Organisational } \\
\text { focus }\end{array}$} & Stimulate industry-wide innovation \\
\cline { 2 - 2 } & Build supply chain maturity \\
\cline { 2 - 2 } & Build sector capacity \\
\cline { 2 - 2 } & Und financial) \\
\cline { 2 - 2 } & Understand time frame for benefits realisation \\
\cline { 2 - 2 } & Integrate service and asset delivery \\
\cline { 2 - 2 } & Manage risk distribution \\
\hline Person focus & Address diverse cohort needs \\
\cline { 2 - 2 } & Address diversity, choice and aspirations in housing needs \\
\cline { 2 - 2 } & Build financial capacity of individuals \\
\cline { 2 - 2 } & Support sustainable and affordable living outcomes \\
\hline \multirow{4}{*}{ Flexibility } & Promote agility and responsiveness \\
\cline { 2 - 2 } & Consider appropriate scalability \\
\cline { 2 - 2 } & Ensure location-specific responsiveness \\
\hline
\end{tabular}

Table 2 - Social procurement criteria (Kraatz 2018b)

\section{Conclusion}

To address issues of access to appropriate social and affordable housing in Australia, and build the socio-economic resilience of the housing system, we need to acknowledge several structural issues which present as a pressing and complex problem. The key challenges highlighted at the beginning of this paper are: the changing demographics of our population; the legacy of our 20th (perhaps even 19th) century housing and community typologies; changing societal expectations of housing and community; and the rise of housing as commodity.

Four niche solutions are discussed in this paper, being tiny houses, elder cohousing, inclusionary zoning and the use of vacant infrastructure. These have been selected as they 
potentially present as both social and economic solutions, which can be delivered as a part of a social procurement approach through Government, the private sector, and/or by NFPs. Key issues need to be addressed however, to enable them to play a more effective role:

(1) Whilst there are significant motivations for, and growing interest in tiny housing, there are significant issues to be addressed to mainstream this niche solution, particularly in terms of all layers of regulatory mechanisms.

(2) The elder co-housing model requires significant commitment on behalf of those establishing and maintaining the community. It does however offer the potential to address the need for new community and social models for an aging population. It also provides a pathway to greater acceptance in the Australian environment for mainstreaming liveable housing design and co-housing models.

(3) Inclusionary zoning presents political issues for governments (at all levels in Australia) and economic issues for those financing developments. It is potentially a key element in making significant inroads into the social housing waiting lists, and the need for well-located and affordable housing for key workers.

(4) The use of vacant infrastructure, whilst a niche and contentious solution, needs consideration as a short-term option to provide safety for the growing group of homeless peoples in our cities and towns.

Traditional planning solutions and processes need to be challenged to facilitate solutions such as those above. And traditional procurement approaches are struggling to address social housing waitlists and the shortage of affordable housing (to buy or rent) in appropriate locations. Social procurement and more agile thinking around these issues is needed, with new tools to facilitate this thinking and delivery being required. Fundamental and large-scale structural change however will only be part of the road towards building a 
more resilient system. Small scale, diverse and niche solutions need to be an integral and supported part of the structural change in Australia's housing system.

Whilst we may feel that such change is beyond our sphere of influence, we can make significant contributions by building a robust evidence base. We can promote and inform the evidence base which:

(1) Builds new housing and community typologies which builds a diverse and resilient housing system.

(2) Shares data to build a sound forward looking demographic profile of our community to inform planning and housing policy and delivery.

(3) Acknowledges the central role of housing in maintaining individual, societal and economic health and wellbeing.

(4) Informs policy making in Commonwealth, State, Territory and Local Government agencies.

(5) Informs private sector asset and service delivery to enable them to deliver social as well as economic and environmental value as part of a business as usual approach.

(6) Communicates to both the community and politicians in appropriate and accessible language to build societal understanding rather than division.

And whilst out-of-the-box solutions may be challenging, they can be addressed with some innovative and collaborative thinking and action within our own individual and organisational spheres of influence.

\section{Acknowledgements:}

This research has been developed with funding and support provided by Australia's Sustainable Built Environment National Research Centre (SBEnrc) and its partners. 
Core Members of SBEnrc include Aurecon, BGC Australia, Queensland Government, Government of Western Australia, New South Wales Roads and Maritime Services, New South Wales Land and Housing Corporation, Curtin University, Griffith University and Swinburne University of Technology. Research inputs from the Curtin research team for Project 1.54 Procuring Social and Affordable Housing are also acknowledged.

\section{References}

AHURI. (2017, 17 Mar 2017). "Understanding Inclusionary zoning: Utilising land use planning systems to deliver affordable housing." $\underline{\text { AHURI Brief Retrieved } 16}$ November 2018, from https://www.ahuri.edu.au/policy/ahuri-briefs/Understandinginclusionary-zoning.

Anglicare Australia (2017). Anglicare Australia Rental Affordability Snapshot. Canberra, Australia.

Australian Bureau of Statistics. (2013). "8752.0 - Building Activity, Australia, Jun 2013: Average Floor Area of New residential Dwellings " Retrieved 05/10/18, from http://www.abs.gov.au/AUSSTATS/abs@.nsf/Previousproducts/8752.0Feature\%20Ar ticle1Jun\%202013.

Australian Bureau of Statistics (2015). Household and Family Projections, Australia 2011 to 2036, Cat no. 3236.0. Canberra, Australia.

Australian Bureau of Statistics. (2016). "2016 Census Quick Stats." Retrieved 7 March 2018, from

http://quickstats.censusdata.abs.gov.au/census_services/getproduct/census/2016/quick stat/SSC51218.

Australian Institute of Health and Welfare (2017). Australia's welfare 2017. Canberra, Australia.

Australian Institute of Health and Welfare. (2018). "Housing assistance in Australia 2018."

Retrieved 15 Match 2019, from https://www.aihw.gov.au/reports/housingassistance/housing-assistance-in-australia-2018/contents/priority-groups-and-waitlists.

Australian Institute of Health and Welfare (2018). Housing assistance in Australia 2018. Australia. 
Australian Psychological Society and Swinburne University (2018). Australian loneliness report: A survey exploring the loneliness levels of Australians and the impact on their health and wellbeing. Australia.

Australian Tiny House Association. (NA). "Building Code." Retrieved 15 November 2018, from https://australiantinyhouseassociation.org.au/building-regulations/.

Buitelaar, E. and G. D. Kam (2012). "The Emergence of Inclusionary Housing: Continuity and Change in the Provision of Land for Social Housing in the Netherlands." Housing, Theory and Society 29(56-74).

Camero, K. (2017, 28 November 2017). "Pop-up shelter for older women under housing stress to open in Melbourne." Retrieved 22 Jan 2018, from https:/www.thefifthestate.com.au/innovation/residential-2/pop-up-shelter-for-olderwomen-under-housing-stress-to-open-in-melbourne.

Cheng, L. (2016). "NSW government introduces draft design guide for medium-density housing. ." Retrieved 28 November 2018, from http://architectureau.com/articles/nsw-government-introduces-draft-design-guide-formedium-density-housing/.

Chilvers, M., et al. (2016). NSW Human Services Outcomes Framework: application to social housing: Shared Outcomes Workshop. Sydney, Australia, NSW Families and Community Services.

Chilvers, M. (2017). Delivering social outcomes: moving from policy to practice. National Housing Conference. Sydney, Australia, AHURI.

Cigdem, M., G. Wood and R. Ong (2015). Australian demographic trends and their implications for housing subsidies. Melbourne, Australia.

City of Freemantle. (2019). "The Freo Alternative (Local Planning Scheme Amendment No. 63)." Retrieved 15 March 2019, from https://mysay.fremantle.wa.gov.au/Freo Alternative.

Community Housing Industry Association (2018). National Plan for Affordable Housing. Canberra, Australia.

Commsec (2017). "Australian home sizes shrink to 20-year low ". Retrieved 05/10/18, from https://www.commbank.com.au/guidance/property/commsec-home-size-trendsreport-201711.html.

CoreLogic (2016). Housing Affordability Report - December 2016. Australia.

Cutter, S., et al. (2018). "A place-based model for understanding community resilience to natural disasters." Global Environmental Change 18: 598-606. 
Evans, K. (2018). "Overcoming Barriers to Tiny and Small Home Urban Integration: A Comparative Case Study in the Carolinas." Journal of Planning Education and Research. https://doi.org/10.1177\%2F0739456X18788938

Families Australia. (2018). "Loneliness: a growing national challenge." Retrieved 15 March 2019, from https://familiesaustralia.org.au/loneliness-a-growing-national-policychallenge/.

Farha, L. (2017). Report of the Special Rapporteur on adequate housing as a component of the right to an adequate standard of living, and on the right to non-discrimination in this context, UN General Assembly.

Fayazi, M. and G. Lizarralde (2013). "The role of low-cost housing in the path from vulnerability to resilience." International Journal of Architectural Research 7(3): 146167.

Fernández Rodríguez, J. F. and D. Czischke (2016). Cross-sector collaboration in housing management. From the Dutch housing associations model to the case of Spain. ENHR 2016. Belfast, Ireland.

Glass, A. (2014). "Elder Cohousing and Other Self-Directed Intentional Communities: Looking out for each other as we grow old." Retrieved 9 November, 2018, from http://www.geron.uga.edu/eic/elderintentionalcommunities.html.

Glass, A. P. (2013). "Lessons Learned From a New Elder Cohousing Community." Journal of Housing for the Elderly Volume 27(4): 348-368.

Government of the Netherlands. (2013). "Spatial Planning in The Netherlands." Retrieved 15 March 2019, from https://www.government.nl/topics/spatial-planning-andinfrastructure/spatial-planning-in-the-netherlands.

Green Building Council of Australia (GBCA) (2015). "Green Star." Retrieved 7 June 2019, from https://new.gbca.org.au/green-star/ .

Greenhalgh, E. (2015b). Planning for Affordable Housing in Queensland. Brisbane, Australia.

Greenhalgh, E. and C. Bosman (2016). "Planning for the supply of more affordable housing: the case of the Queensland Urban Land Development Authority." Australian Planner 53(3): 211-220.

Grounded Solutions Network, Lincoln Institute of Land Policy and National Housing Conference. (2018). "Inclusionary Housing." Retrieved 16 November 2018, from https://inclusionaryhousing.org/about/. 
Gurran, N., S. Rowley, V. Milligan, B. Randolph, P. Phibbs, C. Gilbert, A. James, L. Troy and R. v. d. Nouwelant (2018). Inquiry into increasing affordable housing supply: Evidence-based principles and strategies for Australian policy and practice. Melbourne, Australia.

Inclusionary Housing. (2016). "Inclusionary Housing Database Map." Retrieved 15 March 2019, from https://inclusionaryhousing.org/map/.

Inclusionary Housing. (2018). "Inclusionary Housing Calculator 2.0." Retrieved 15 March 2019, from https://inclusionaryhousing.org/calculator/.

Kraatz, J. (2018a). Social Procurment Approaches. Brisbane, Australia: Sustainable Built Environment National Research Centre.

Kraatz, J. (2018b). Social Procurment Criteria. Brisbane, Australia: Sustainable Built Environment National Research Centre.

Kraatz, J., M. E. Z. d. Baro and P. Newman (2018). Changing demographics and housing typologies. Brisbane, Australia: Sustainable Built Environment National Research Centre.

Kraatz, J. and N. Jayawardena (2018). 360 Degree Survey Findings. Brisbane, Australia: Sustainable Built Environment National Research Centre.

Kraatz, J. A., M. Z. d. Baro and P. Newman (2018). Changing Demographics and Housing Typologies. Brisbane, Australia: Sustainable Built Environment National Research Centre.

Kraatz, J. A., J. Mitchell, A. Matan and P. Newman (2015). Rethinking Social Housing: Effective, Efficient and Equitable - Final Industry Report. Brisbane, Australia: Sustainable Built Environment National Research Centre.

Kraatz, J. A. and G. Thomson (2017). Valuing Social Housing: Final Research Report. Brisbane, Australia: Sustainable Built Environment National Research Centre. LandCorp (2015). WGV White Gum Valley Design Package. Perth, Australia: LandCorp. LandCorp (2016). Affordable Housing Design Competition Brief: Designed for Shoreline Perth. Australia: LandCorp.

LandCorp. (2019a). "Our Role." Retrieved 15 March 2019, from https://www.landcorp.com.au/About-Us/Our-Role/.

LandCorp. (2019b). "Innovation through demonstration: WGV White Gum Valley." Retrieved 15 March 2019, from https://www.landcorp.com.au/innovation/wgv/. LandCorp. (2019c). "Initiative GenY project." Retrieved 15 March 2019, from https://www.landcorp.com.au/innovation/wgv/initiatives/Gen-Y-House/ 
Lawson, J., H. Pawson, L. Troy, R. v. d. Nouwelant and C. Hamilton (2018). Social housing as infrastructure: an investment pathway. Melbourne, Australia, AHURI.

Livable Housing Australia. (2019). "Welcome to Livable Housing Australia." Retrieved 15 March 2019, from http://www.livablehousingaustralia.org.au/.

Nobel, L., A. Carter, V. Bares, R. Pieters, B. Winkle, K. Meathrel, H. Shearer and F. Caniglia (2017). A Place for Tiny Houses: Exploring the Possibilities - Tiny House Planning Resource for Australia 2017. Australia: The Tiny House Company.

O'Sullivan, F. (2018). "How Temporary Tiny Homes Could Solve Dutch Cities' Housing Crises." Retrieved 5 December 2018, from https://www.citylab.com/design/2018/11/dutch-housing-shortage-temporary-tinyhomes-construction/576610/.

Pogliani, L. (2016). A new frame for Social Housing Affordability in Italy. ENHR 2016. Belfast, Ireland.

Pradolin, R. (2018, 20 August 2018). "Women over 55 years now the fastest growing homeless people in Australia." Retrieved 16 November 2018, from https://www.afr.com/real-estate/women-over-55-years-now-the-fastest-growinghomeless-people-in-australia-20180819-h146r2.

Queensland Department of Housing and Public Works. (2017). "Density and Diversity Done Well: Open Ideas Competition." Retrieved 28 November 2018, from http://statedevelopment.qld.gov.au/planning/density-and-diversity-done-well-openideas-competition.html.

Queensland Department of Housing and Public Works (2017a). Queensland Housing Strategy 2017-2027. Brisbane, Australia: QDHPW.

Queensland Government (2017b). Queensland Housing Strategy 2017-2020 Action Plan: Building a better housing future for all Queenslanders. Brisbane, Australia: QDHPW. Rappaport, L. (2018). Inclusionary zoning in Canada? Key Considerations from US Municipalities. Winnipeg.

Shearer, H. (2017). "Interest in tiny houses is growing, so who wants them and why?" The Conversation.

Shearer, H. and P. Burton (2018). "Towards a Typology of Tiny Houses." Housing, Theory and Society. https://doi.org/10.1080/14036096.2018.1487879

Thomas, R. (2013). "Resilience and housing choices among Filipino immigrants in Toronto." International Journal of Housing Policy. 13(4): 408-432. 
Vail, K. M. (2016). "Saving the American Dream: The Legalisation of the Tiny House Movement " University of Louisville Law Review 54(3): 357-395.

Victorian State Government (2018). Victoria's social procurement framework: Building a fair, inclusive and sustainable Victoria through procurement. Melbourne, Australia.

Wahlquist, C. (2018). 'Loneliness minister' proposed to tackle Australian social isolation. The Guardian. Australia.

Walker, P. (2018). May appoints minister to tackle loneliness issues raised by Jo Cox. The Guardian. Australia.

Western Australia Housing Authority (2015). Affordable Housing Strategy 2010-2020: Aiming Higher. Government of Western Australia.

Xia, B., et al. (2015). "Sustainable retirement village for older people: a case study in Brisbane, Australia." International Journal of Strategic Property Management 19(2): $149-158$.

Yang, J. and Z. Yang (2015). "Critical factors affecting the implementation of sustainable housing in Australia." Journal of Housing and the Built Environment 30: 275-292.

Yates, J., B. Randolph, D. Holloway and D. Murray (2005). Housing affordability, occupation and location in Australian cities and regions. Sydney, Australia: AHURI.

Zandt, S. V., Peacock, W.G., Henry, D.W., Grover, H., Highfield, W.E., and S.D. Brodyet (2012). "Mapping social vulnerability to enhance housing and neighborhood resilience." Housing Policy Debate 22(1): 26-55. 